\title{
Socioeconomic and Health Condition of Elderly Migrants in Monterrey City, Mexico
}

\author{
Arun Kumar Acharya \\ Instituto de Investigaciones Sociales, Universidad Autónoma de Nuevo León \\ Av. Lázaro Cárdenas Ote. y Paseo de la Reforma S/N, Campus Mederos U.A.N.L., \\ C.P. 64930 , Monterrey, Mexico \\ Tel: +52(81) 83294237 \\ E-mail address: acharya_77@yahoo.com
}

\begin{abstract}
Present paper attempts to analyze the socioeconomic condition of elderly migrants and their impact on health status. About 156 Mexican elderly migrants were interviewed in Monterrey Metropolitan Region during 2010-12. The study found that, majority of elderly migrates in search of a better economic opportunity in urban areas. Once they arrive to city, they absorb in informal economic sectors. Our results indicate that most of the elderly do not have any job contract as well as they also earns very less compared to younger migrants. Most of the time employers ask them to work more hours without extra salary, which has adverse effect on their health. Elderly migrants were reported numerous health problem, whereas many of them were suffering from high risk diseases such as heart problem, obesity, high \& low blood pressure, asthma among others. Present study concluded that socioeconomic difference has great impact on health status of the older population.
\end{abstract}

Keywords: Elderly migrants; socioeconomic condition; informal economy; health vulnerability; Mexico

\section{INTRODUCTION}

Population ageing is a global phenomenon, which is having and will have major implications on all aspects of human life in every society. This process is enduring and irreversible, as observed from differing patterns and distinct paces in various regions and countries all over the world. The United Nations has undertaken various efforts to draw governments' attention to answers to these encompassing and profound demographic changes. Various initiatives have taken place at global as well as at regional and sub-regional level to highlight the pressing need for concerted action. In this regards numerous agreements formulated at the global conferences on social development, population and women by the United Nations in the 1990s, which all refer to ageing as an issue of particular concern (CEPAL, 2004) $)^{1}$.

United Nations declared the year 1999 was as "International Year of Older Persons". More than a decade has passed since then and it is essential that we take stock of the advancement done to improve the welfare of the ageing population. Some years back, this ageing issue was a concern of mostly for European countries, which had already completed

\footnotetext{
${ }^{1}$ http://www.cepal.org/celade/noticias/paginas/8/14928/lccarg772.pdf
} 
their demographic transition. Today, population ageing has become a global phenomenon with serious implications for the developing countries as well. Consequently, governments in developing countries have started developing plans and programs to address the challenges posed by ageing.

According to Population Division of United Nations, currently 11 per cent of world populations were more than 60 years and over, which projected to 22 percent by 2050 , and it estimated that 36 per cent of this global aged population are living in the industrialized, more developed nations of the world (United Nations, 2011a). These countries have low fertility levels, which will ultimately generate populations exhibiting a high proportion of elderly persons. In Latin America and the Caribbean region, the demographic transition is under way and the population is gradually but inexorably ageing. This is a generalized process, in which all the countries are advancing towards the "graying" of their societies. Two characteristics of this process make it a matter of urgent concern. First, the population is ageing at a more rapid pace, and will continue to do so in the future, than the rates recorded in the past by today's developed nations. Second, this is taking place to a high poverty rate as well as a social inequity, a low level of institutional development and changes in family structure and composition (ECLAC, 2003).

As a result of immense demographic changes in other part of the world, Mexico is also experiencing profound changes in its demographic scenario in last 50 years. Data indicates that Mexican population over 60 years has increased from 5 during 1960 to 9 per cent in 2009 and expected to 28 per cent by 2050 (United Nations, 2010). It also estimated that by 2020, 1 in every 10 Mexican maybe older than 60 years. This shift in age structure is associated with population ageing has a profound impact on a broad range of economic, political and social conditions.

Mexico's population has aged significantly in the past two decades. In 2010, the median age was 26 years meaning that there were equal numbers of people above and below age 26 . The median age in 2000 was 22 years while that in 1990 was only 19 years. Obviously, the number of older adults is growing much faster than the number of young adults and children. The Federal District has the highest median age by far with 31, followed by Nuevo León, Tamaulipas and Veracruz with 27. At the other end are Chiapas with 22, Guerrero with 23, and Puebla, Guanajuato, Durango and Aguascalientes with 24 (Rhoda and Burton, 2010).

The study of Rhoda and Burton (2010) indicates; that in 2010, about 29.3 percent of the Mexican population was under age 15, compared to 34.1 percent in 2000 and 38.6 percent in 1990. On the other hand, the 2010 census reflects that 6.3 percent are over age 65 , up from 5.0 percent in 2000 and only 4.2 percent in 1990. The proportion in this older age group increased 50 percent in the past two decades. These changes are quite dramatic and represent major demographic change. The trend expected to continue and have significant implications for health, elder care systems and regional demographic imbalance through migration.

Research on elderly population with relation to migration and their health issues is quite few in Mexico, as because, elderly migrants are not as much as other age groups, their floating rate is low; also, people think studying on migrants labors, migrants women and migrants children are important since they may face employment, reproduction and education problems. As far as statistics indicates, floating elderly population is still under count, but currently it rising, for instance in Mexico only 3.7 percent elderly population were migrants in, which reaches to 5 percent in 2010. Many demographic researches indicates that it will continue increasing in the future alone with the increasing of the elderly population, the increasing of the single child family and the acceleration of urbanization. 
Taking into consideration the above discussion, present paper intend to explore the socioeconomic and health condition of elderly migrants in Mexico. In this study we have examines the principal reasons of elderly migration to urban centers, their salary structure as well as their current health problem. The present research carried out in Monterrey city, one of the highly industrialized urban center in Mexico as well as it is situated close US border. For this research, we have interviewed 156 elderly internal migrants (migrated to Monterrey prior to two years before at the time of interview) during 2010-12 with a semi structure questionnaire, who are working in the informal sector.

\section{SOCIOECONOMIC AND HEALTH: THEORY AND EVIDENCE}

It is well defined the positive association between socioeconomic status and health condition. For example; among older adults in Britain and the United States, a move from the top education or income tercile to the bottom tercile is associated with an increase of at least fifteen percentage points in the likelihood of reporting fair or poor health (Banks et al. forthcoming, in Cutler. et. al, 2008). In the case of Mexican elderly the poorest and least educated terciles reporting poor health at least ten percentage points more often than the richest and most educated terciles (Smith and Goldman 2007, in Cutler. et. al, 2008).

There are literatures who provides good theoretical insights into the relation between the socioeconomic and health status, for example Mirowsky and Ross (2008) stated that better education generates good health status among the people as knowledge and skill are able to better self manage illness and disease. On the other hand, income is an important variable that promote good health by affecting nutrition, housing quality, exposure to environmental hazards, stress and access to adequate health care (Cohen, Farley and Mason, 2003, Lantz et. al, 2005). The study of Evans and Katrowitz (2002) indicates that; there is a strong relation between lowincome persons and poor health. According to these authors, poor people are particularly vulnerable because they may be unable to afford adequate physical and mental health care, limited in terms of access to healthy food and subject to living in toxic environments and unhealthy housing conditions. Recent research suggests that income associates more strongly with progression (rather than onset) of disease than does education (Herd, Goesling, and House, 2007; Zimmer and House, 2003), suggesting that economic resources promote health in part by increasing the abilities to pay for medical care and to acquire transportation to care facilities.

On the other hand, literature on migration analyses patterns and causes indicates that people migrate to urban centers or countries in search of a better livelihood. For example, Weber et al. (2007) examined a subsample of the US Panel Study of Income Dynamics dataset for 1993, consisting of 701 migrants and non-migrants household heads aged 25-64 residing in nonmetropolitan counties. They also employed a two-stage-probit model to explain the direct and indirect effects of migration and concluded that migration has bring out better-quality jobs, health and living status for rural adults, which have direct effect on quality of life. The relationship between socioeconomic status and health is not difficult to document. In most countries, at each age those in higher income or wealth groups are in much better health. These differences are quantitatively large. For example, in the US the fraction reporting excellent health among the highest income quartile is 40 percentage points higher than those in the lowest quartile (Smith 1999). The health-income gradient widens until around age 50 after which it gradually contracts (see Figure 1). 


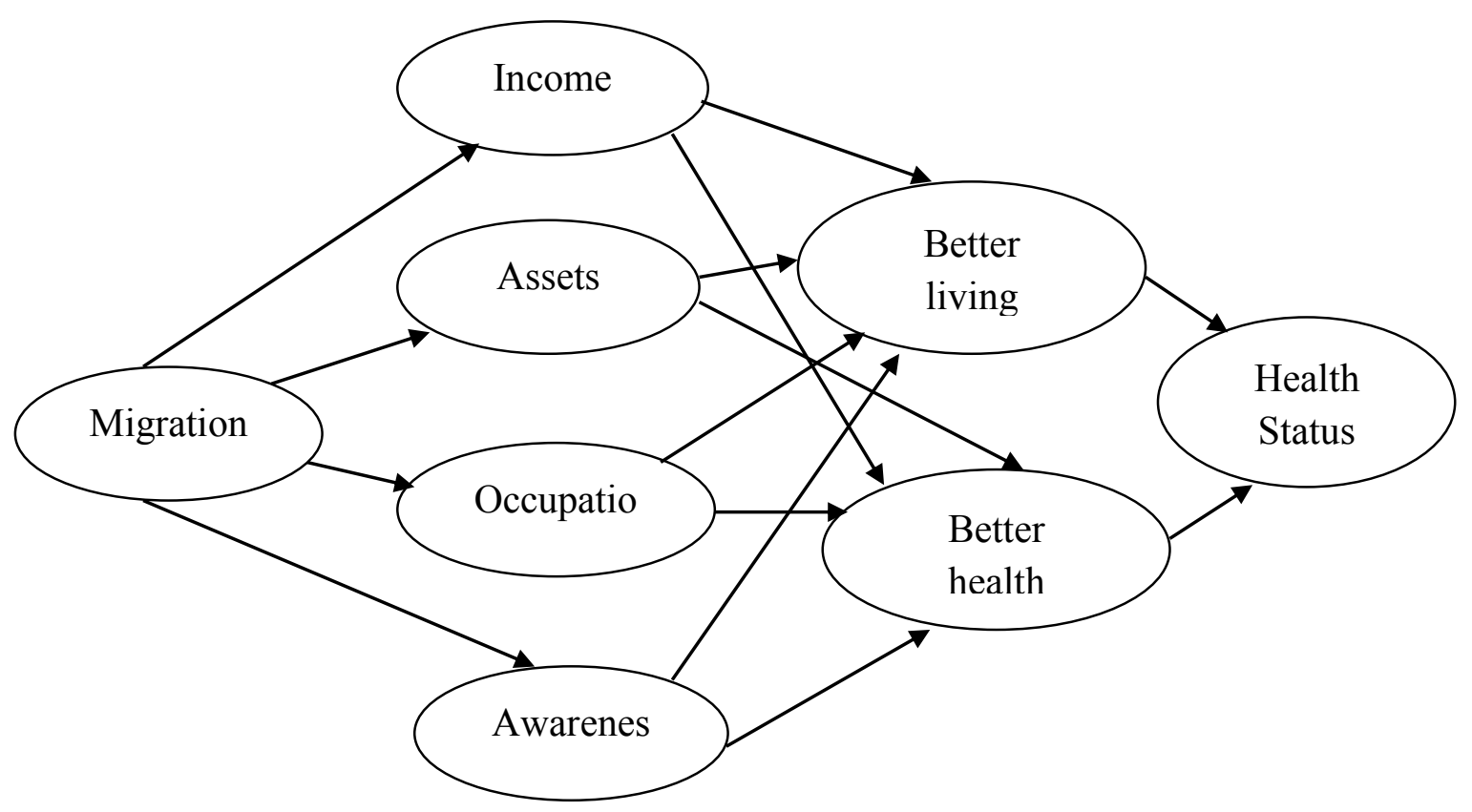

Figure 1. Effect of Migration on Health status.

Thus, health problem for adult or aged people is not only a biological or medical concern but also a significant personal and socio-economical concern. On the issue of migration of elderly people Wiseman's (1980) in his behavioral model explained that older people migrate in search of better residential satisfaction. According to author, the idea of migration can be stimulate by one or more triggering mechanisms, which include change in life cyclical stage, age related losses and critical events, environmental incongruence, change in preferred lifestyle and forced movement. These mechanisms reflect by various pull factors, for example, kinship networks and push factors such as environmental stress. The movement of older people is affect by a set of endogenous and exogenous factors. The endogenous factor comprises personal resources such as income, health status including their experiences on migration, whereas, exogenous factors are related to the living cost, housing market and their social network.

On the other hand, Northcott's (1988) in his social demographic model provides an explanatory framework for migration decision. Migration of older people depends on both objective factors and subjective factors. Objective factors such as personal characteristics such as; age, income, health features of the place origin and destination i.e. access to services, amenities, presence of kin and friends and intervening obstacles such as distance and cost of moving, can have direct impact of decision to move. The indirect effects of objective factors can also be exerted through the decision making process such as declining health, familial relationship etc,. Although subjective factors have direct effects on mobility, the model also emphasizes the role of certain objective attributes such as social class and ethnicity in shaping one's attitudes, values and expectations, which turn, influence the migration decision.

From the above discussion, it is assume that currently elderly migration is purely economic movement, which has directly related to their health status. It is true in the case of developed nations, where elderly people have economic and social security, but at present, there are developing countries where ageing process is growing concern and due to absence of social and economic security elderly people migrate to different urban centers in search of employment, mainly in informal sector. This aspect has not widely discussed, and thus this 
paper has focused on elderly migration in the case of Mexico and stated that this migration flow is purely an economic based like as other migration flow and has lots of impact on their socioeconomic and health status.

\section{DEMOGRAPHIC PROFILE OF MEXICO}

Mexico's demographic transition has followed a typical profile, the pre-transitional phase that lasted until about 1930, the first stage saw a rapid decline in mortality while birth rates remained fairly steady and even rose between 1945 and 1960. The second phase began around 1970 when the decline in fertility, which began during the 1960s, became more rapid. The third stage of the process, when the birth and mortality figures converge, will occur during the first half of the twenty-first century. During the year 1921, the population growth rate was 1.4 percent and it was 1.7 percent in 1930 and further to 2.7 percent in 1950 and 3.5 percent in 1965. Consequence of the decline in fertility, the pace of population growth then began gradually to decrease, to 3.1 percent in $1970,2.3$ percent in $1985,1.3$ percent in 2000 and currently it is less than 1 percent (Partida-Bush, 2005).

The general falls in mortality was so rapid that the cumulative reduction in the risk of death between 1930 and 2001 amounted to 82 percent for men and 86 percent for women. As in many other countries, Mexican mortality fell slowly during the 1960s. The pace of decline picked up later, but was not as rapid as in earlier years. A rapid and sustained decline in mortality took place beginning in the 1930s, in a context of far-reaching economic, political and social reforms. Among the main determinants of the sharp decline in mortality are the expansion of education services and sanitation infrastructure and the extension of health services. The latter has been a significant factor ever since the creation of the Mexican Social Security Institute (IMSS) in 1942 and the conversion of the Department of Health into the Ministry of Health in 1943. On the other hand, in 1930, the life expectancy at birth was 35.9 years, whereas, in 2010 it was 75.6 years. Progress was greatest between 1942 and 1960 when there was an increase of almost one year in the average length of life for each calendar year (Partida-Bush, 2005).

The decline in fertility did not begin until the mid-1960s. The high and even rising rates before then reflected the pro-natalist policy prevailing in the country during those years. Families had about six children in the early twentieth century, reaching a maximum of 7.2 children at the beginning of the 1960s. The gradual spread of the practice of family planningas part of a new policy that sought to regulate population growth in accordance with the agreements adopted at the 1974 United Nations World Population Conference in Bucharestcontributed to advancing the fertility transition in Mexico. The total fertility rate (TFR) fell to six children per woman in 1975, five in 1979, four in 1985 and three in 1994, and has now reached to 2.1 children (Partida-Bush, 2005).

The various phases of demographic transition have left their mark on the age structure of the Mexican population, as can be seen from the figure 1. The data indicates that during the decades 70s Mexico had the demographic transition, for which we can observe a fall in the 0 to 4 and 5 to 9 age groups population and a sharp increase in 20 to 40 as well as elderly population. From the figure 1 it is appear that, after the years 1990 the elderly population in Mexico has started increasing at a higher rate compared other age groups, except 20 to 40 (INEGI, 2011) 2.

\footnotetext{
${ }^{2}$ Estadísticas a Propósito Del Día Internacional De Las Personas De Edad, INEGI, 2011 http://www.inegi.org.mx/inegi/contenidos/espanol/prensa/default.asp?c=269\&e, 05-05-2012
} 
According to Instituto Nacional de las Personas Adultas Mayores (INAPAM) currently about 10 million ( 9 percent of total population) are elderly population and it is expected to reach 15 million in 2015 and 36 million in $2050^{3}$.

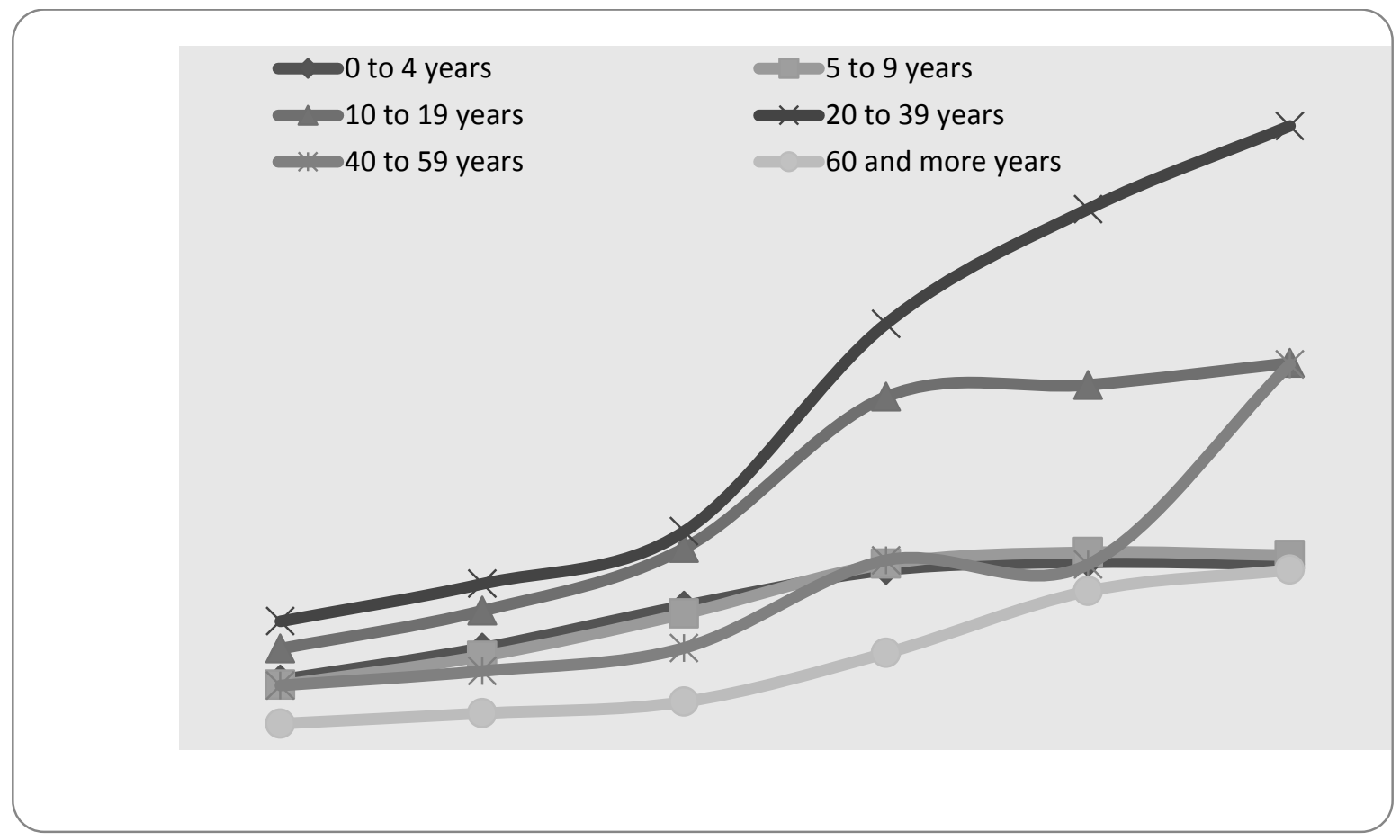

Figure 1. Population distribution according to age groups in Mexico during 1950-2010.

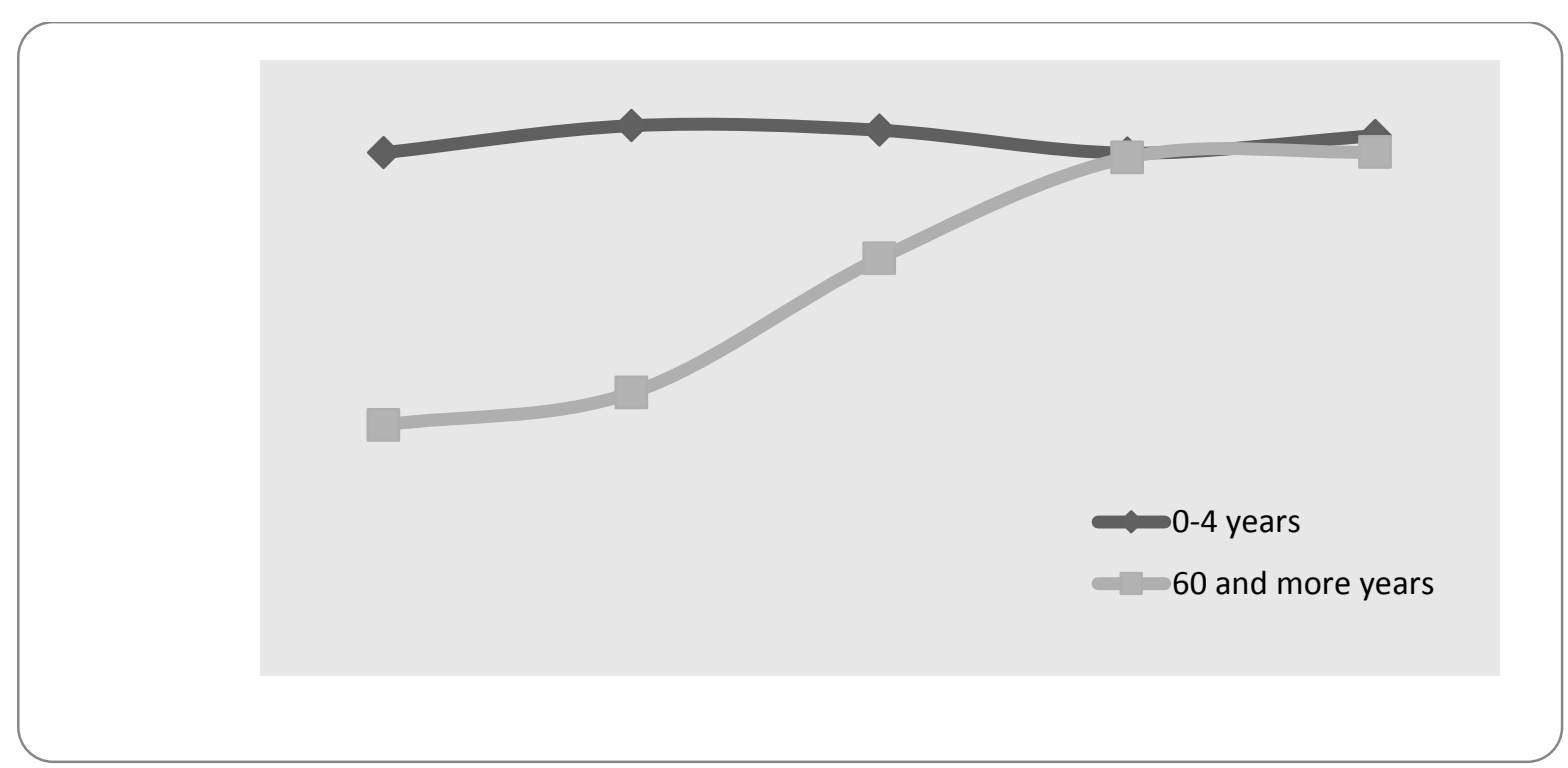

Figure 2. Infant and elderly population distribution in Mexico during 1990-2010.

On the other hand, we have analyze the population of 0-4 years and 60 years and more during the years 1990, 1995, 2000, 2005 and 2010 (see figure 2). From the flowing figure, we can clearly observe that in after 1995 there is steady growth in elderly population $(60+$ years)

\footnotetext{
${ }^{3} \mathrm{http}: / /$ www.inapam.gob.mx/index/index.php?sec=16\&clave_articulo=136\&formato=print, 05-05-2012
} 
and at the same time; the 0-4 population is declining. During the year 2005 there was a transition between infant and elderly population in Mexico, which explained that Mexico is moving toward a ageing society.

It is a clear indication that elderly population in rise in Mexico, but according to Consejo Nacional de Evaluación de la Política de Desarrollo Social (CONEVAL) in 2010 around 3.5 million elderly people are suffering from multidimensional poverty, whereas around 0.8 million are suffering from extreme multidimensional poverty. Data indicates that among 3.5 million elderly 66.2 percent were illiterate, whereas 26.3 percent were do not have any kind health services, 28.8 percent didn't have any kind of social security and around 22 percent elderly had limited alimentation (INEGI, 2012) ${ }^{4}$. Data of elderly people living in rural areas indicates that they need to work in order to secure a minimum income for their survival. Due to absence of universal pensions systems and any kind governmental help are non-existent in rural Mexico, thus these ages people prefer to migrate to urban centers in search of employment. It has seen that upon their arrival elderly people occupied in the informal sector. In the figure 3 we have interpreted how the number of elderly migrants increasing in informal sector in the case Monterrey city. The figure shows that though there is little decline during 2000-05 in number of elderly in informal sector, but it increases after 2008, due to global economic crisis.

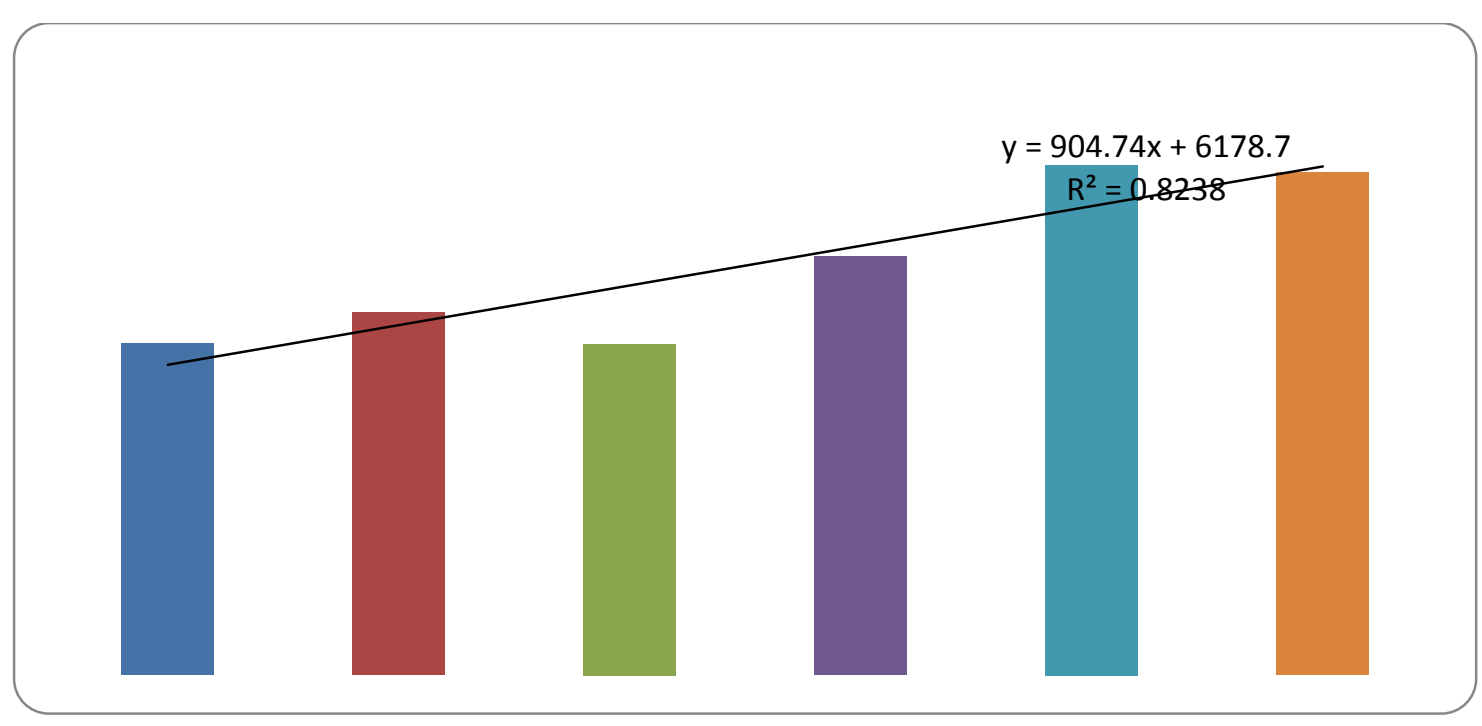

Figure 3. Number of elderly migrants in informal sector in Monterrey.

\section{DEMOGRAPHIC FEATURES OF ELDERLY MIGRANTS IN MONTERREY}

Literature on migration indicates that migration is a phenomenon of younger ages, which no longer may be true and we have seen in this analysis. Table 1 provides a full descriptive summary on demographic characteristics of elderly migrants. Among the 156 participants, the major fraction (81 percent) of the elderly migrants' population was in the age group of 61-70 and 80 years old, while a small part are 51-60 and more than 80 years old. In term of literacy and educational attainment, we have obtained that nearly 70 percent of elderly migrants are educated up to primary and secondary level.

\footnotetext{
${ }^{4}$ INEGI (2012), Estadísticas a Propósito del día del Niño, datos nacionales, Aguascalientes, AGS., a 30 de abril de 2012.
} 
Illiteracy rate is very low; around 13 percent were never attained school. Data indicates that more than 50 percent elderly migrants are currently living with their spouse and whereas one third of the respondent reported, they are widow (see Table 1).

Table 1. Demographic distribution of elderly people in Monterrey.

\begin{tabular}{|c|c|}
\hline Elderly Migrants & Percentage \\
\hline Age & \\
$52-60$ & 14.1 \\
$61-70$ & 51.9 \\
$71-80$ & 29.5 \\
More than 80 & 4.5 \\
& \\
Education & \\
Illiterate & 13.1 \\
Up to primary & 47.9 \\
Up to secondary & 29.7 \\
Bachelor and more & 9.2 \\
& \\
Marital status & 3.0 \\
Never married & 56.2 \\
Married/Living with partner & 28.3 \\
Widow & 12.4 \\
Divorced and separated & \\
\hline
\end{tabular}

\section{OCCUPATION, MONTHLY INCOME AND DYNAMIC OF EMPLOYMENT OF ELDERLY MIGRANTS}

Capron and Arellano (2010) pointed out that elderly migrants are more vulnerable compared to other migrants due to their ages. These categories of migrants struggle to get a decent job, thus they preferred to occupy in the informal sectors.

Data in employment status of elderly migrants shows that (see Figure 4) nearly 28 percent of migrants engaged as street vendor, whereas 17 percent were domestic servant and sweeper. Some elderly migrants also worked as taxi driver, labor at construction site, mechanic and others.

It is clearly observe that; there is a high segregation of elderly migration at "outdoor jobs" (52 percent), which is a big concern for the health as well as safety of these people 


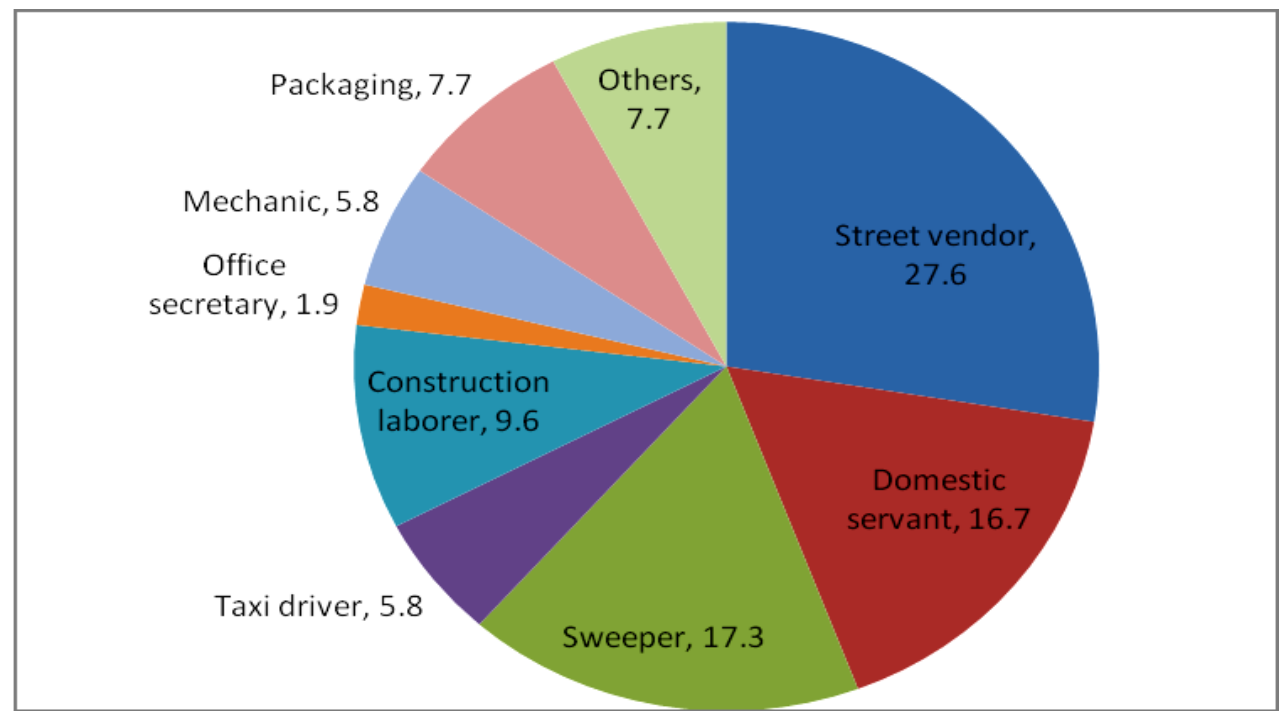

Figure 4. Occupation of elderly migrants in Monterrey.

To understand the quality of life and impact on health of elderly migrants, we asked a question on their monthly income (see Figure 5). Analysis found that 18 percent of elderly migrants receive less than 1500 pesos $^{5}$ per month and nearly 43 percent of elderly migrants earn in between 1500 to 3000 pesos per month, whereas 17 percent of migrants said their monthly income is 3000 to 4,000 pesos. However, we found that nearly one-fourth earn more 4000 pesos per month.

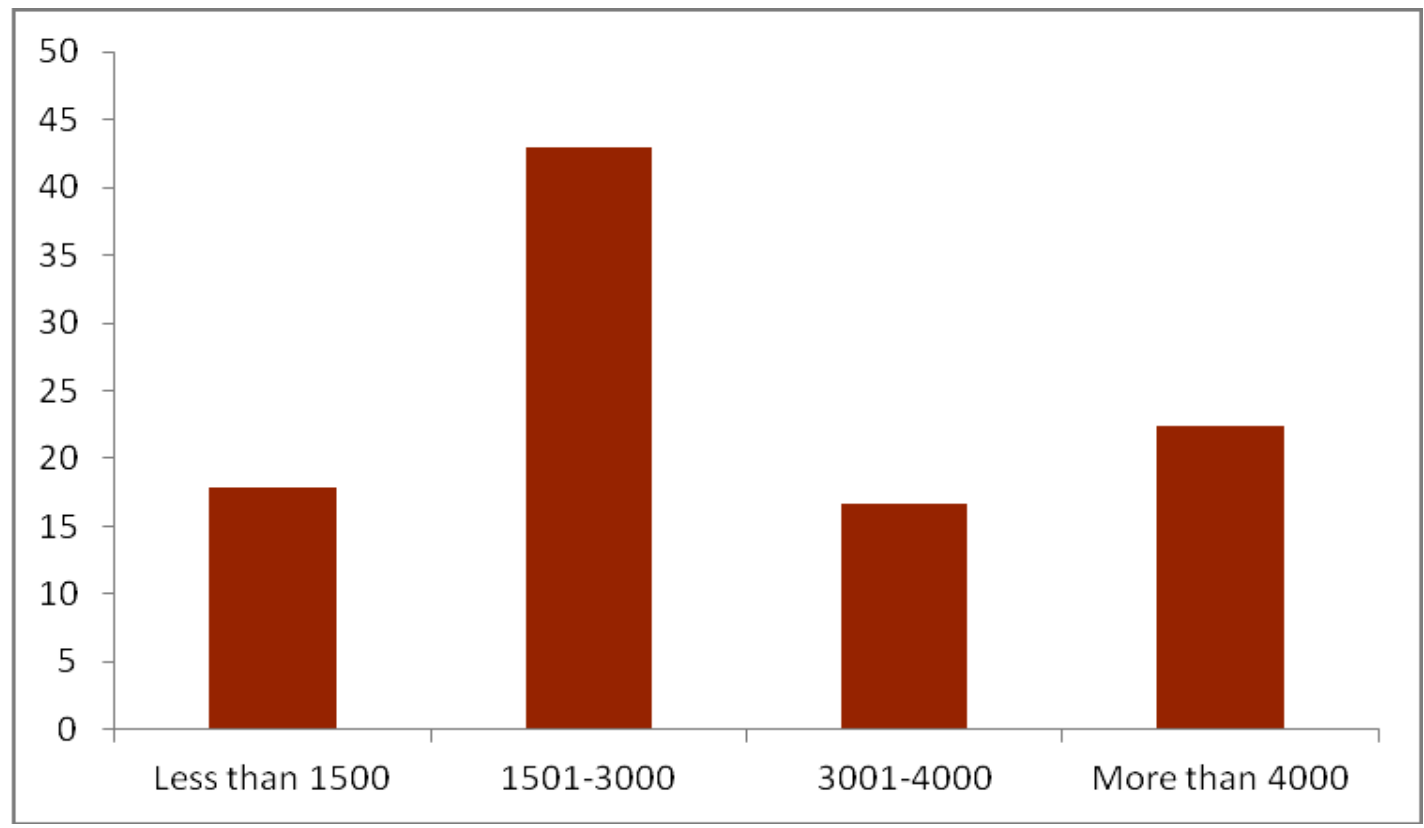

Figure 5. Monthly income of elderly migrants in Monterrey.

\footnotetext{
${ }^{5}$ In Mexico 12 pesos is $\$ 1$ USD
} 
The analysis on dynamic of employment includes the status of job contract, job stability and work shift. It is observe that only 18 percent elderly migrants have job contract, which indicate that 82 percent work without any contract, which indicates lack of stability in their job. Thus, on question of job stability, we found that nearly 69 percent migrants posses a daily basis contact, whereas 17 percent migrants said their contract is monthly basis and nearly 14 percent migrants have their contract for few weeks (see Table 2). The question on working shift, we have seen that majority ( 71 percent) migrants have morning shift, 20 percent migrants' works in afternoon and 9 percent work during night. Above results indicate that elderly migrants are more vulnerable towards the job exploitation, as they do not possess any fixed and signed contract, as well as their job stability is very less and even there are migrants who are working during the night.

Table 2. Dynamic of employment of elderly migrants in Monterrey.

\begin{tabular}{|c|c|}
\hline Dynamic/employment & Percentage \\
\hline Job Contract & 17.9 \\
Yes & 82.1 \\
No & \\
Job stability & \\
Daily wage contract & 69.2 \\
Monthly contract & 17.3 \\
Few weeks contract & 13.5 \\
& \\
Work shift & 71.3 \\
Morning & 19.5 \\
Afternoon & 9.2 \\
Night & \\
\hline
\end{tabular}

\section{HEALTH STATUS OF ELDERLY MIGRANTS}

To survive in the city, migrants must work hard and must adjust with living environment and condition. In this section, we have analyzed the health status of elderly migrants in Monterrey city. Table 3 indicates the perception of elderly migrants on self-perception on their health status. It has seen that nearly 38 percent male 41 percent female migrants said they have good or fair health, whereas 62 percent male and 59 percent female migrants had poor health perception.

Table 3. Self-perception on health status by elderly migrants in Monterrey.

\begin{tabular}{|c|c|c|}
\hline Self-perception on health status & Male & Female \\
\hline Fair health & 37.9 & 40.6 \\
Poor health & 62.1 & 59.4 \\
\hline
\end{tabular}


When we asked question on general health problem suffered by elderly migrants, we found that more than half of the elderly migrants (both male and female) reported various physical problems. The problems such as joint pains, muscles pain, stress, feeling week and skin diseases are common for both man and women. However, other health problem for example hearing problem, vision problem and memory loss some other diseases represented and reported by elderly migrants (see Table 4).

Table 4. Reported general health problem reported by elderly migrants.

\begin{tabular}{|c|c|c|}
\hline Health problem & Male* $^{*}$ & Female* $^{*}$ \\
\hline Joint problem & 80.5 & 76.8 \\
Hearing problem & 43.7 & 47.8 \\
Vision problem & 36.8 & 37.7 \\
Feeling weak & 60.9 & 55.1 \\
Memory loss & 25.3 & 26.1 \\
Skin disease & 57.5 & 63.8 \\
Muscles pain & 77.0 & 79.7 \\
Stress & 85.1 & 76.8 \\
\hline
\end{tabular}

* Multiple responses

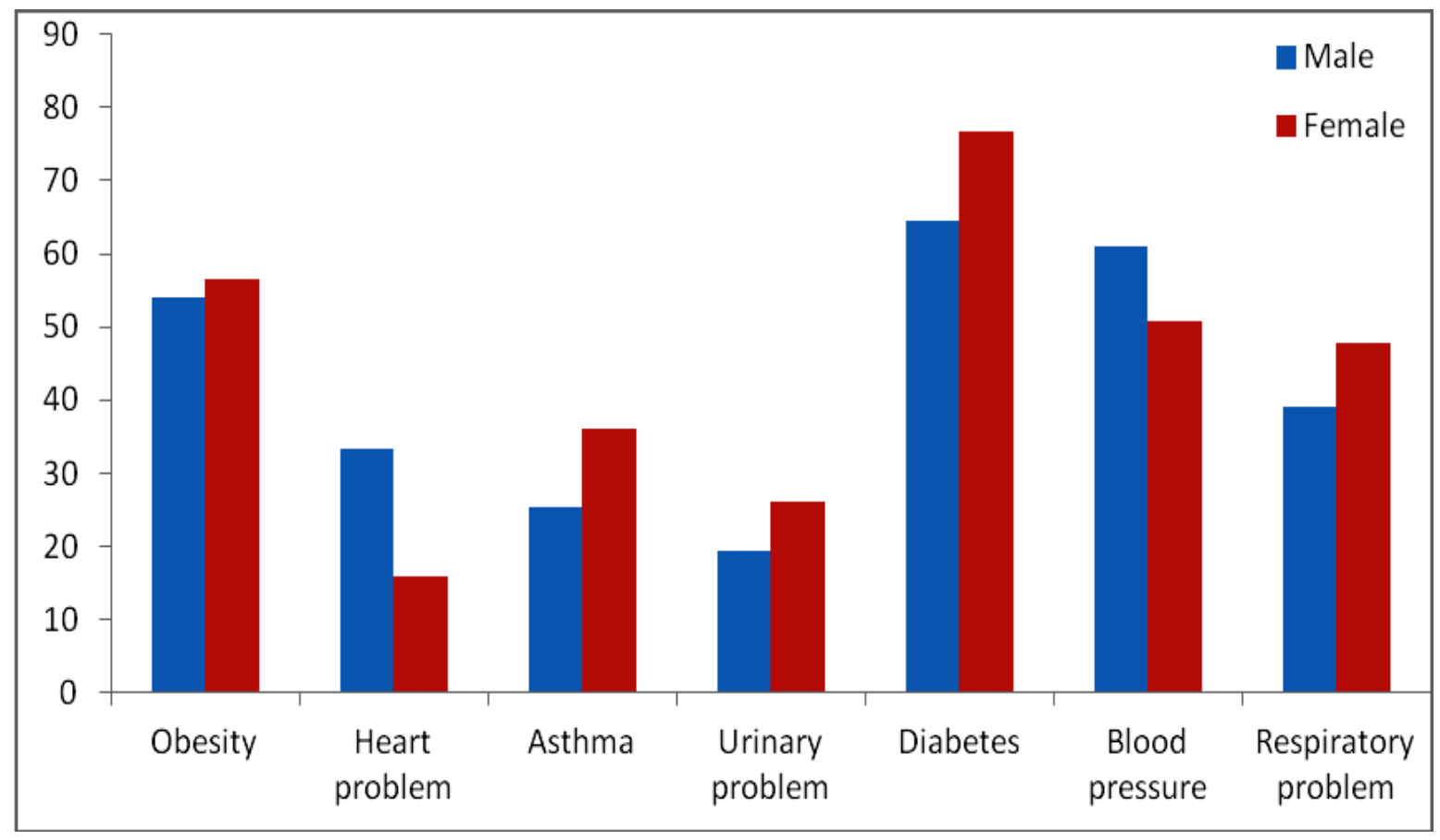

Figure 6. Prevalence of high-risk diseases suffered by elderly migrants in Monterrey. 
However, in this study we have classified and analyzed the prevalence of high-risk diseases suffered by the elderly migrants in Monterrey. The percentage of high-risk diseases such as obesity, diabetes and high \& low blood pressure are significantly higher among both men and women. More than half of interviewed elderly migrants reported these problem. However, the prevalence of diseases such as heart diseases is higher among male (33 percent) than female (16 percent). Other high risks diseases such as asthma and urinary problem are also high among the elderly migrants (see Figure 6).

\section{QUALITY OF LIFE AND ITS IMPACT ON HEALTH STATUS}

To measure the impact of quality of life on health status first we have calculated the standard of living index (SLI). The SLI calculated taking into consideration the socioeconomic variables, which has divided into three categories, such as higher, medium and low. The category high standard living consider those elderly, who own a house with more than 4 rooms, have at least a car, all kinds of electronic assets and air condition. Medium category of living standard of living includes elderly who rented a house, having all kinds of electronic goods, have a car and no air condition in their house. The low standard of living includes those migrants who do not have at least a rented house they are staying with their friends or in hurt, do not posses and electronic goods as well as car and air condition. From the table we can observe that, nearly 15 percent male and 7 percent female have high standard of living index. On the contrary, 61 percent of male and female elderly migrants have medium standard of living whereas it is interesting to observe that almost twice percentage of elderly migrant women have high category of standard of living and similarly more women (nearly 32 percent) have low category of SLI compare to 24 percent of men.

The Table 5 indicates the relationship between the standard of living index on health of elderly migrants. It can be observe that elderly migrants' posses' high living standard index reported fair or health condition compared to medium and low categories of SLI. On the other hand, when we analyzed the poor health condition of elderly migrants, it has seen that those migrants' posses medium and low SLI significantly higher level of poor health condition.

Table 5. Standard of living and its impact on health of elderly migrants.

\begin{tabular}{|c|c|c|}
\hline Standard of living Index (SLI) & Fair health & Poor health \\
\hline High & 33.1 & 12.6 \\
Medium & 37.9 & 62.1 \\
Low & 29.0 & 25.3 \\
\hline
\end{tabular}

On the contrary, we have done similar bi-variate analysis only taking into consideration the standard of living index and two major acute national health problems, i.e. obesity and diabetes. Result indicates that low percentage of elderly migrants of high and medium SLI (4.1 and 32.7 percent) reported these diseases compared to migrants of low SLI (63.2 percent). Thus, our study demonstrated that there is strong association between the socioeconomic conditions of elderly migrants with their health status. 


\section{DISCUSSION AND CONCLUSION}

Migration is a fact of today's globalised world and increasingly a necessary component of economic and social development everywhere. As migration is increasingly becoming a part of life, the health implications of migration and the health of migrants need to be recognize as an important issue in health policy. Migrants go through several experiences, which ultimately affect their health particularly in settings where they face a combination of social, cultural, economic and behavioral barriers during the migration process. Socioeconomic inequities exist in every society and between different societies mean that the freedom to lead flourishing lives and enjoy good health are unequally distributed amongst different population groups and migrants frequently find themselves amongst those most negatively affected by these imbalances, as we observed from our earlier discussion.

It is evident from the study that there is an increasing number of elderly people in the migration network, who migrate in search of employment and better opportunity, as they do not receive any social security from government, including for some elderly their pension is not sufficient. Insufficient employment opportunities in formal sector for elderly push to informal sector, where they worked as street vendor, taxi driver, mechanic, sweeper and domestic servants without any contract and social security. As we have seen from the analysis elderly migrants do not earn according to their expectation, majority of elderly migrants earn 1500 to 3000 pesos per month. Thus, there is a strong discrimination against elderly migrants in term of salary as well as in their working hours and day. Study found that these migrants hardly get time to take rest during weekend. For most of them weekend does not exist. Some migrants work six days in a week and there are high number of elderly who works seven days of a week.

Our analysis on health status of elderly migrants, as expected many migrants reported various health problems, but the most common health issues faced by migrants are joint problem, muscle pain, stress and feeling weakness. Similarly, analysis indicates there is a high prevalence risky disease such as obesity, diabetes and blood pressure among the elderly migrants, which significantly point out the poor and alarming health outcome among the groups. However, our bi-variate analysis on socio-economic condition and health outcome indicates there is correlation between two. Elderly migrants who posses better socioeconomic condition in term of standard of living have better health outcome comparing the elderly of medium and low socioeconomic groups. In general, we have obtained a considerable association between socioeconomic status and poor health status of migrant elderly population. As literature on the subject of migration, ageing and health indicates that socioeconomic difference has great impact on health status of the older population. Hence, one important thing needed is to fill a critical gap in the research of migration of elderly population and public health studies are to quantify the socioeconomic inequalities in health status.

\section{References}

[1] Capron, Guénola and Arellano, Salomón González. (2010). "Movilidad residencial de los adultos mayores y trayectorias de vida familiares en la Zona Metropolitana de Valle de México". Alteridades 20 (39), México.

[2] Cohen Deborah A., Thomas A. Farley, Karen Mason, "Why Is Poverty Unhealthy? Social and Physical Mediators". Source Social Science \& Medicine 57 (2003). 
[3] Cutler, David M, Lleras-Muney, Adriana and Vogl, Tom. (2008). "Socioeconomic Status and Health: Dimensions and Mechanisms". Working Paper 14333, http://www.nber.org/papers/w14333, National Bureau of Economic Research, 1050 Massachusetts Avenue, Cambridge, MA 02138, September 2008.

[4] ECLAC (Economic Commission for Latin America and the Caribbean). (2003). Regional strategy for the implementation in Latin America and the Caribbean of the Madrid international plan of action on ageing, Santiago, Chile, 19-21 November.

[5] Evans Gary W., Elyse Katrowitz E. (2002). "Socioeconomic Status and Health: the Potential Role of Environmental Risk Exposure". Annual Review of Public Health 23 (2002).

[6] Herd Pamela, Brian Goesling, James S. House., "Socioeconomic Position and Health: The Differential Effects of Education versus Income on the Onset versus Progression of Health Problems". Journal of Health and Social Behavior 48 (2007).

[7] INEGI (Instituto Nacional de Estadísticas y Geografía) (2012). Estadísticas a Propósito del día del Niño, datos nacionales, Aguascalientes, Abril.

[8] Kanaiaupuni Shawn (2000). "Leaving Parents Behind: Migration and Elderly Living Arrangements in Mexico", CDE Working Paper, No. 99-16, Center for Demography and Ecology, University of Wisconsin-Madison.

[9] Lantz Paula M., James S. House, James M. Lepkowski, David R. Williams, Richard P. Mero, Jieming Chen. (1998). "Socioeconomic Factors, Health Behaviors, and Mortality: Results from a Nationally Representative Prospective Study of US Adults." Journal of the American Medical Association 279 (2008)

[10] Longino C. F. (1992). "The forest and the tress: Micro level considerations in the study of geographic mobility in old age". In Elderly Migration and Population Redistribution, ed. A Rogers, 23-24, London, England, Belhaven Press.

[11] Mirowsky John, Catherine E. Ross, "Education and Self-Rated Health: Cumulative Advantage and Its Rising Importance". Research on Aging 30 (2008).

[12] Northcott H. C. (1988). Changing residence: The geographic mobility of elderly Canadians, Toronto, Ontario, Butterworths.

[13] Partida-Bush Virgilio (2005). "Demographic transition, demographic bonus and ageing in Mexico". In Population Division: Department of Economic and Social Affairs, United Nations expert group meeting on social and economic implications of changing population age structures, UN/POP/PD/2005/16, Mexico City, Mexico.

[14] Rhoda, Richard and Burton, Tony. (2010). Geo-Mexico: the geography and dynamics of modern Mexico, Frostburg State University, MD.

[15] Rogers, A, ed. (1992). Elderly migrants and population redistribution. London, England: Belhaven Press.

[16] United Nations. (2011a). World Population Prospects: the 2010 Revision. Department of Economic and Social Affairs, Population Division, New York, USA.

[17] United Nations. (2011b). World Population Ageing-Profiles of Ageing 2011. Department of Economic and Social Affairs, Population Division, CD-ROM Edition, New York, USA. 
[18] Valerio, Christy. (1997). Elderly Americans: Where They Choose to Retire. Garland Publication.

[19] Weber Bruce, Alexander Marre, Monica Fisher, Robert Gibbs, John Cromartie, "Education's Effect on Poverty: The Role of Migration". Review of Agricultural Economics 3 (29) (2007).

[20] Wiseman R. F. (1980). "Spatial aspects of Aging". Association of American Geographers Resources. Paper for College Geography, No. 78-4, Washington, DC. Association of American Geographers.

[21] Wong, Rebeca, Espinoza, Mónica, Palloni, Alberto. (2007). “Adultos mayores mexicanos en contexto socioeconómico amplio: salud y envejecimiento". Salud Pública de México, 49 (4), Cuernavaca.

[22] Zimmer Zachary, James S. House., International Journal of Epidemiology 32 (2003) 1089-1097 